Editorial

\title{
Empowering survivors after the cure
}

\author{
Volume 5 Issue 3 - 2016
}

\section{Editorial}

Few days ago I met a handsome man in his forties who stopped me telling that I cured him when he was an eight years old boy, suffering from a non Hodgkin lymphoma. I recognized his name, and asked about his family and himself. He told me that he was an Engineer working in building cruise ships, a very exiting job, his parents were fine, his wife was wonderful, and two daughters were beautiful and outstanding at school. Our talk was going on for at least ten minutes; he showed to be a happy, positive, strong, healthy man.

In the last years our literature about survivors produced a lot of articles about empowering patients and families. ${ }^{1}$ I thought that he was a real good success in these terms, being a survivor. Since the seventies we pushed all our sick children to be positive, to go to school, to attend their peers, to play sports, to have enthusiasm in every moment of their lives, to be strong because they would be cured, because their wish to heal was crucial. We helped them to successfully reorganize their lives despite the disease, treatments and various difficult situations. Our first aim was to teach resilience. ${ }^{2}$ And how to cope with their new condition, to teach the family caregivers what it was expected from them. ${ }^{3-5}$

Prompted by a curiosity to better understand the outcomes and quality of life of the survivors of the same age, we found that 49 over 60 were living. They were treated in our Division between 1974 and 1978. The last check they had in our out patient Department was in 2002. We wrote a personal letter to all 49 , asking them to answer simply with the description of their life, health status, family, education, occupation, emotions, marriage and children, and also their feelings about their past disease and hospital care. 43 answered. The group included 24 males and 19 females. They were very glad to have been contacted after a long time and wrote us the letter, mostly a very long letter, touching their past, present and future hopes.

Their answers were quite a surprise for us, firstly because it was clear that they wished to have this new contact with us, second because they were the confident voice of a winner, of someone who had survived the shipwreck and had reached a safe port after battling through the waves. Their words were expressing a true empower they had achieved, good physical, cognitive, emotional and behavioral development and adjustment: "if I won the disease, nothing else frighten me, I want to enjoy every positive opportunity that I can meet in my life". I feel really proud on the work done on each child by all of us and especially of the psychological team in the last forty years.

\section{Words written in their letters by our patients treated from I 974 and 1978}

"Fear has transformed in immense happiness: my healing was a miracle... The experience changed my life, but I'm here and I can tell it. "

"This experience has made me stronger than before: I learned that if you want to achieve something you have to fight to the end for her. I got it done; now it is your turn!"

\author{
Luisa M Massimo \\ Department of Pediatric Hematology and Oncology, G. Gaslini \\ Scientific Children's Hospital, Italy
}

Correspondence: Luisa M. Massimo, Department of Pediatric Hematology and Oncology, G. Gaslini Scientific Children $\square s$ Hospital, Genoa, Italy, Email luisamassimo@gaslini.org

Received: September 16, 2016 | Published: June 02, 2016

"The dedication of doctors and nurses allowed me to get to what I am today, happy to write this letter. They taught me with the passage of time to see the world with an optimistic view".

"Today I am a sensitive, strong, determined person, accepting the challenge of the obstacles that arise. If you encounter obstacles it makes me regain lucidity and strength to try to deal with them"

"This experience has changed me inside and it is a gift that I perceive with intensity today. Having to deal with the kids who made fun of me made me stronger".

"The healing has given me a feeling that allows me to understand people and their pain."

"I feel stronger; I can find an energy inside me that makes me react to find a solution without stopping".

"Each person must not miss a single moment. You have to enjoy everything, be strong and positive. Laugh and smile are our strength".

"It is important to give and to receive a smile; it gives a vibration in each of our experiences".

"My testimony today that I am a man of 45 years old, married and father of a son, the only scars I carry are those on the body, those that healed me."

"After the expiry of the fateful five years, I yelled to my mother who is in heaven "Mom I am healed! We made it". Today, with my husband and my son I am happy".

"The disease is passed. It did not let anger towards life, indeed helped me to love it even more and to live happiness".

"I resumed my beautiful life; I studied and went to run even faster on the football field with the wish of a goal!"

"The disease was not a negative experience, indeed an opportunity that gave me a critical view on life".

"After so many years, the scar is still bad, but it does not bother me. It reminds me that I was on the brink. Now I enjoy my life and I continue to live with joy".

"Life is great if you are healthy. Now I am healthy and it is a wonderful thing".

\section{Acknowledgments}

None. 


\section{Conflicts of Interset}

None.

\section{References}

1. Sadak KT, Connor C, DeLuca H. Innovative educational approaches to engage and empower the adolescent and young adult childhood cancer survivor. Pediatr Blood Cancer. 2013;60(12):1919-1921.

2. Wieland A, Wallenburg CM. the influence of relational competencies on supply chain resilience: a relational view. Intern J Physical Distribution and Logistics Management. 2013;43(40):300-320.
3. Boman KK, Bodegard G. Life after cancer in childhood: social adjustment and educational and vocational status of young-adult survivors. J Pediatr Hematol Oncol. 2014;26:(6):354-362.

4. Haupt R, Spinetta JJ, Ban I, et al. Long term survivors of childhood cancer: cure and care. The Erice statement. Eur $J$ Cancer. 2007;43(2):1778-1780.

5. Seitzman RL, Glover DA, Meadow AT, et al. Self-concept in adult survivors of childhood acute lymphoblastic leukemia a cooperative Children's Cancer Group and National Institutes of Health study. Pediatr Blood Cancer. 2004;42(3):230-240. 